\title{
Spreadsheet Modelling of Grain Size Evolution during Rod Rolling
}

\author{
T. M. MACCAGNO, J. J. JONAS and P. D. HODGSON" ${ }^{1}$
}

Department of Metallurgical Engineering, McGill University, 3450 University Street, Montreal, Canada H3A 2A7. E-mail: Johnj@Minmet.Lan.Mcgill.Ca 1) BHP Research, Melbourne Laboratories, 245 Wellington Road, Mulgrave, Victoria, Australia 3170.

(Received on October 24, 1995; accepted in final form on January 18, 1996)

\begin{abstract}
An analysis was conducted of the pass-by-pass evolution of austenite grain size during the rod rolling of plain carbon steel. This was achieved by organizing previously-developed equations relating grain size and hot working parameters into a commercial computer spreadsheet program. By considering the substantial "redundant" strains developed during rod rolling, the analysis reveals that metadynamic recrystallization (MRX) is the dominant microstructural process, and this is confirmed by the mill grain size measurements reported previously. The spreadsheet was also employed to examine the effects of modifications to rod rolling practice aimed at refining the austenite grain size. Little benefit is obtained by increasing the strain rate or by reducing the distance from the final rolling pass to the laying head. On the other hand, increasing the cooling rate on the forced-air cooling deck should lead to measurable grain refinement. Lowering the temperature during rolling can lead to even more refinement, and various strategies to achieve this are discussed.
\end{abstract}

KEY WORDS: rod rolling; static recrystallization; dynamic recrystallization; metadynamic recrystallization; kinetics; austenite grain size; redundant strain; desktop computers; spreadsheets.

\section{Introduction}

During the early stages of rod rolling, the pass strains are usually high enough to initiate dynamic recrystallization (DRX). In the case of rod finishing, although the nominal pass strains are below the critical strain for DRX, the interpass times are too short for significant amounts of conventional static recrystallization (SRX) to occur. ${ }^{1)}$ As a result, the strain accumulates from pass to pass until DRX is initiated. This is the case even for plain carbon-manganese grades. ${ }^{1,2)}$ At the completion of a pass involving DRX, the recrystallization that occurs is no longer "dynamic"; rather, it is "metadynamic" (or "post-dynamic"). ${ }^{3,4)}$ Previous work ${ }^{1,2,5,6)}$ indicates that metadynamic recrystallization (MRX) can result in fine austenite grain sizes at high values of the Zener-Hollomon parameter; i.e. at high strain rates and relatively low temperatures. In one sense, the real importance of DRX during hot rolling is that it sets the stage for MRX.

When the interpass times are too short for significant amounts of SRX to occur, the rolling practices that exploit this grain refinement potential can be termed "metadynamic recrystallization" controlled rolling. When the interpass times are too short even for significant MRX to occur, the practice can be referred to as "dynamic recrystallization" controlled rolling. ${ }^{5,6)}$ (Note, however, that the latter is not the case for the rod finishing of plain $\mathrm{C}-\mathrm{Mn}$ grades. This is because enough time is available for substantial MRX, even during interpass intervals as short as $0.01 \mathrm{sec}$, as a result of the high driving forces that are generated. See Sec. 2.2 below.) MRX controlled rolling schedules can only be designed for tandem (i.e. short interpass time) rolling processes because the relative absence of carbonitride precipitation, as well as of SRX, are both prerequisites. ${ }^{2)}$ This contrasts with the better known "conventional" controlled rolling (CCR) and "recrystallization" controlled rolling (RCR) types of schedule applicable to reversing mills, during which precipitation and SRX, respectively, are required to take place.

In the past, the physical simulation of rolling schedules-for example, by means of laboratory torsion testshas proved to be very helpful in the design of rolling practices for reversing mills. ${ }^{2,78)}$ However, the high strain rates associated with the finishing stages of tandem mills (up to $1000 \mathrm{~s}^{-1}$ or higher in rod mills, and up to $200 \mathrm{~s}^{-1}$ in strip mills), cannot readily be achieved using laboratory equipment. As a result, it is difficult to carry out physical simulations to provide grain size information that is directly applicable to rod finishing (and, to a lesser extent, to strip finishing). MRX controlled rolling practices, therefore, have not attained the high levels of development and optimization associated with CCR and RCR schedules. To some extent, this can be overcome by carrying out computer simulations of rolling that employ equations relating the grain size to the hot rolling parameters.

In the present paper, an approach is outlined whereby the evolution of austenite grain size during rod rolling is modelled by incorporating the relevant equations into 
commonly-used spreadsheet software. The model is then employed to examine the effects of several possible modifications to the current rolling practice for plain carbon steel wire rod. The overall aim of performing these calculations was to explore the potential for refining the austenite grain size by means of MRX controlled rolling.

\section{Austenite Grain Size Evolution during and after Hot Rolling}

\subsection{Grain Size Evolution Equations}

Over the years, several research groups have developed equations relating the evolution of austenite grain size $d_{\gamma}$ to the hot rolling parameters. A recent overview is provided by Hodgson and Gibbs. ${ }^{9)}$ These equations have been incorporated in our laboratory into a commercial spreadsheet (for example, Microsoft Excel* ${ }^{*}$, or Lotus $\left.1-2-3^{* *}\right)$.

In the first step of the procedure, the critical strain $\varepsilon_{\mathrm{c}}$ required to initiate DRX is calculated, since the softening mechanism operative after each pass-either conventional static recrystallization, or metadynamic (i.e. postdynamic) recrystallization-depends on whether the pass strain is less than or greater than this value. It is calculated from the grain size at the start of the pass $d_{\mathrm{o}}$, the strain rate $\dot{\varepsilon}$, and the absolute temperature $T$ (degrees $\mathrm{K})^{10}$ ):

$$
\varepsilon_{\mathrm{c}}=5.6 \times 10^{-4} d_{\mathrm{o}}^{0.3} Z^{0.17}
$$

where $Z=\dot{\varepsilon} \cdot \exp (300000 / 8.31 T)$ is the Zener-Hollomon parameter. This sharp demarcation between SRX and MRX at $\varepsilon_{c}$ is probably somewhat of an over-simplification, as it implies that the occurrence of a small amount of DRX during the deformation is sufficient for the entire structure to recrystallize by MRX afterwards. Nonetheless, this appears to be supported by studies showing that the recrystallization kinetics are virtually independent of strain for deformations beyond the DRX peak strain, and possibly even for deformations only slightly higher than $\varepsilon_{\mathrm{c}^{-}}{ }^{6,11}$ )

The recrystallized fraction $X$ after a given pass can be specified by a form of the Avrami equation:

$$
X=1-\exp \left(-0.693\left(\frac{t}{t_{0.5}}\right)^{q}\right)
$$

where the Avrami exponent $q$ and the time for $50 \%$ softening $t_{0.5}$ depend on whether the softening is by SRX or $\mathrm{MRX}^{9,11)}$,

if $\varepsilon<\varepsilon_{\mathrm{c}}$ (i.e. when SRX occurs), then

$$
t_{0.5}=2.3 \times 10^{-15} \varepsilon^{-2.5} d_{\mathrm{o}}^{2} \exp \left(\frac{230000}{8.31 T}\right)
$$

if $\varepsilon>\varepsilon_{\mathrm{c}}$ (i.e. when MRX occurs), then

$$
t_{0.5}=1.1 Z^{-0.8} \exp \left(\frac{230000}{8.31 T}\right)
$$

equations were developed using fractional softening data, which include components due to both recovery and recrystallization. However, in what follows, it has been assumed that they are accurate for describing the kinetics of recrystallization alone. This only leads to small errors in the analysis, particularly as the main focus is on the completion of recrystallization, which coincides with the completion of softening.

If the softening is by SRX, and there is sufficient time for the recrystallization to proceed to completion, the grain size (in $\mu \mathrm{m}$ ) is given by ${ }^{9,11}$ ).

$$
d_{\mathrm{SRX}}=343 \varepsilon^{-0.5} d_{\mathrm{o}}^{0.4} \exp \left(\frac{-45000}{8.31 T}\right)
$$

Similarly, the grain size after complete MRX is ${ }^{9,11)}$ :

$$
d_{\text {MRX }}=2.6 \times 10^{4} \cdot Z^{-0.23}
$$

It is worth noting here that the equations for $t_{0.5}$ and $d$ were originally developed to describe the behaviour under isothermal conditions, while the temperature during hot rolling is continuously changing. This can be taken into account by using the "temperature-compensated time" approach adopted by Sellars and coworkers, ${ }^{12)}$ or the "additivity rule" of Scheil. ${ }^{13)}$ However, in the present work, the interpass times were judged to be short enough for $t_{0.5}$ and $d$ to be computed at a single temperature, the one corresponding to the simple average of the prior and subsequent passes.

Grain Coarsening: For the rod rolling of plain $\mathrm{C}$ grades, the interpass time $t_{\mathrm{ip}}$ is usually much larger than that required for complete MRX (from Eq. (2), $t_{0.95}=2.65 \times$ $\left.t_{0.5}\right)$, and grain coarsening follows recrystallization. Grain coarsening also occurs in the event that there is complete SRX $\left(t_{0.95}=4.32 \times t_{0.5}\right)$. As discussed elsewhere, ${ }^{11,14)}$ there are problems with the currently available grain coarsening equations, and the "pragmatic" approach described by Hodgson et al. ${ }^{11)}$ is adopted here. Basically, grain coarsening at times longer than about $1 \mathrm{~s}$ is well described by equations with the grain size term raised to the power 7 :

for SRX:

$$
d^{7}=d_{\mathrm{SRX}}^{7}+1.5 \times 10^{27}\left(t_{\mathrm{ip}}-4.32 t_{0.5}\right) \exp \left(\frac{-400000}{8.31 T}\right)
$$

for MRX:

$$
d^{7}=d_{\mathrm{MRX}}^{7}+8.2 \times 10^{25}\left(t_{\mathrm{ip}}-2.65 t_{0.5}\right) \exp \left(\frac{-400000}{8.31 T}\right)
$$

but this formulation leads to unrealistically rapid coarsening at shorter times. To get around this, second order equations are employed for times shorter than $1 \mathrm{~s}$ :

for SRX:

where $q=1$ for SRX and $q=1.5$ for MRX. ${ }^{9)}$ These

\footnotetext{
* Trade mark of Microsoft Corp., Redmond, Washington, USA.

** Trade mark of Lotus Development Corp., Cambridge, Massachusetts, USA.
} 


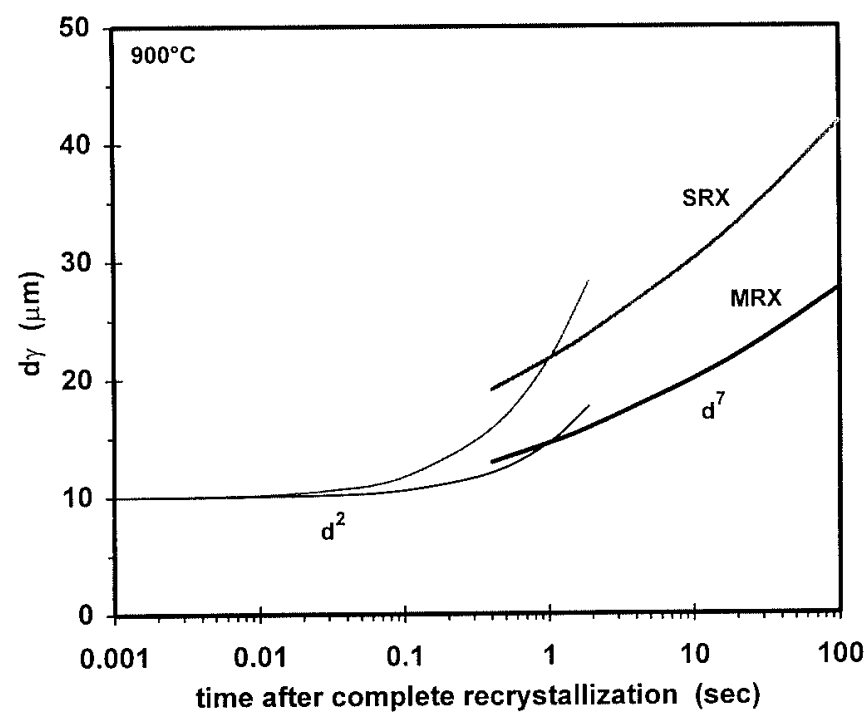

Fig. 1. Austenite grain coarsening behaviour after either full static (SRX) or full metadynamic (MRX) recrystallization. Note the transition from second order to seventh order equations at $1 \mathrm{~s}$.

$$
d^{2}=d_{\mathrm{SRX}}^{2}+4.0 \times 10^{7}\left(t_{\mathrm{ip}}-4.32 t_{0.5}\right) \exp \left(\frac{-113000}{8.31 T}\right)
$$

for MRX:

$$
d^{2}=d_{\mathrm{MRX}}^{2}+1.2 \times 10^{7}\left(t_{\mathrm{ip}}-2.65 t_{0.5}\right) \exp \left(\frac{-113000}{8.31 T}\right)
$$

where the constants are selected so that the second and seventh order curves intersect at around $1 \mathrm{~s}$ (see Fig. 1). The grain size after recrystallization (and coarsening, if any) is then $d_{\mathrm{o}}$ at the entry to the next stand.

Partial Recrystallization: If there is only partial recrystallization between passes, the average grain size at the entrance to the next stand can be calculated from a "law of mixtures" type of relation that takes into account the softened and non-softened grains "inherited" from the previous pass ${ }^{12,14)}$.

$$
d_{\mathrm{o}_{i+1}}=X_{i}^{4 / 3} \cdot d_{\mathrm{RX}_{i}}+\left(1-X_{i}\right)^{2} \cdot d_{\mathrm{o}_{i}}
$$

Here, $d_{\mathrm{RX}}$ is determined from either Eq. (5) or (6), as appropriate. Note that if $X$ is small, there is little change in grain size (that is, there is only a change in grain shape) before the next stand.

Partial recrystallization also results in some strain being retained to the next stand, and the accumulated strain $\varepsilon_{\mathrm{a}}$ is calculated according to the relation ${ }^{9)}$ :

$$
\varepsilon_{\mathbf{a}_{i+1}}=\varepsilon_{i+1}+\left(1-X_{i}\right) \varepsilon_{i}
$$

This is the strain value that is inserted into Eq. (1) to determine whether or not DRX (followed by MRX) is initiated during that pass.

Redundant Strains: The strains at each pass are actually significantly larger than those that would be calculated simply from the reductions in cross-sectional area through the rolling stands. This is because there are two types of "redundant" strain that are developed during rod rolling. The first, which is the larger of the two, is associated with the profile changes such as squareto-oval, oval-to-round, and round-to-oval. It involves plastic work and reversed shears, even when there is no net change in cross-sectional area. The second arises from the finite length of the working zone, and consumes work even in the absence of profile changes. It involves the shear or "folding" of an element of metal when it begins to undergo converging flow in the deformation zone, followed by reverse shear or "unfolding" upon exiting the deformation zone. ${ }^{15)}$ The first type is largely absent in simple flat rolling operations, where the profile remains rectangular throughout, while the second is always present as long as there is friction and/or the deformation zone is relatively short.

The computer model of deformation during rod rolling developed at BHP Steel ${ }^{16)}$ has been employed to calculate the redundant strains associated with specific pass geometries. These simulations indicate that the total strains per pass (including area strain, as well as the two types of redundant strain described above) are factors of 1.5 to 2 times the simple area strains in the roughing passes, and factors of 2 to 3 in all subsequent passes. In the present work, for simplicity, the pass strains were taken to be a constant factor of 1.7 times the area strain for the roughing stands, and 2.5 times the area strain subsequently. That is, the variations in redundant strain factor attributable to the profile changes associated with particular passes are neglected here.

\subsection{Grain Size Evolution after Low and High Strain Rate Deformations}

It was remarked in the Introduction that the large differences between rod mill and laboratory strain rates make it difficult to devise physical simulations that are directly applicable to rod finishing. This problem can be seen more clearly by comparing the evolution of austenite grain size during and after deformation, at mill and laboratory rates. Using the relations given in the previous section, this is demonstrated in Fig. 2 for a temperature of $1000^{\circ} \mathrm{C}$, strain rates of $1 \mathrm{~s}^{-1}$ (lab) and $500 \mathrm{~s}^{-1}$ (mill), and a single applied strain of 0.8 (i.e. well into the DRX regime for both rates)*. Even for scenarios where the starting grain sizes are the same (e.g. $50 \mu \mathrm{m})$, the evolution of $d_{\gamma}$ with time is considerably different for the two rates.

This considerably complicates the task of trying to apply laboratory results to rod finishing conditions. For example, a quench time of 2 or $3 \mathrm{~s}$ after a laboratory test leads to very little coarsening, whereas in the same elapsed time after the last mill stand, there is significant coarsening. Laboratory tests can therefore only be used to confirm existing grain evolution equations (or develop new ones), and these then have to be extrapolated to predict the behaviour at rod mill strain rates. There is no way to simulate the mill behaviour directly.

It can be seen from Fig. 2 that MRX is more rapid

* In Fig. 2, the estimates for $d_{\mathrm{DRX}}$ were obtained from ${ }^{9.11)} ; d_{\mathrm{DRX}}=1.6 \times 10^{4} \cdot \mathrm{Z}^{-0.23}$, while the growth from $d_{\mathrm{DRX}}$ to $d_{\mathrm{MRX}}$ is arbitrarily assumed to be a straight line. 
and results in a finer recrystallized grain size after deformation at the higher strain rate. This can be ascribed to the higher dislocation density $\rho$ generated during the higher rate deformation. Recalling that $\sigma \propto \rho^{1 / 2}$ and that $\sigma \propto \dot{\varepsilon}^{m}$, it is evident that $\rho_{2} / \rho_{1}=\left(\sigma_{2} / \sigma_{1}\right)^{2}=\left(\dot{\varepsilon}_{2} / \dot{\varepsilon}_{1}\right)^{2 m}$. The rate sensitivity $m$ is typically $\sim 0.13$ for steel at hot working temperatures, and this leads to $\rho_{2} / \rho_{1} \sim 5$ in the present case. Such a higher density can be expected to lead to both more numerous nuclei, as well as a higher driving force for recrystallization.

\subsection{Spreadsheet for a $12 \mathbf{~ m m ~ R o d ~ R o l l i n g ~ S c h e d u l e ~}$}

The grain size evolution equations presented in Sec. 2.1 were applied to a 19 pass schedule used for rolling $127 \times 127 \mathrm{~mm}$ square billets down to $12.0 \mathrm{~mm}$ diameter rods. This schedule was chosen because it is one where Hodgson et al. ${ }^{11)}$ actually measured the austenite grain

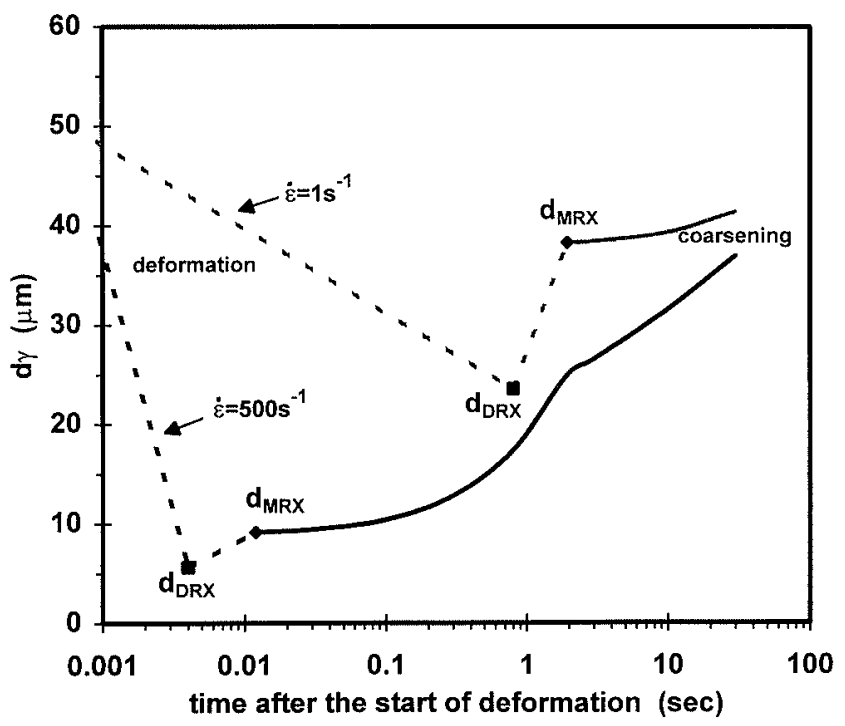

Fig. 2. Austenite grain size evolution during and after deformation at $1000^{\circ} \mathrm{C}$ and two strain rates: laboratory $\left(1 \mathrm{~s}^{-1}\right)$, and mill $\left(500 \mathrm{~s}^{-1}\right)$. size immediately after finishing, and the spreadsheet results can therefore be compared with mill data. The pass-by-pass spreadsheet calculations are shown in Table 1(a) (R: Roughing, I: Intermediate, P: Prefinishing, F: Finishing). Note that there is a $90^{\circ} \mathrm{C}$ temperature drop between stands $\mathrm{P} 2$ and F1 because of water cooling prior to entry into the finishing block.

Because of the magnitude of the redundant strains, the individual pass strains applied in the roughing, intermediate, and prefinishing stands actually exceed those required to initiate DRX. The softening after each pass therefore occurs by MRX. Moreover, according to the kinetics (Eq. (4)), there is sufficient time for complete MRX followed by significant grain coarsening before the beginning of the next pass. An interesting point to observe here is that since the MRX grain size depends only on the strain rate and temperature (Eq. (6)), the grain size at the end of the pass is independent of the grain size at the beginning of the pass. Thus, $d_{y}=24.8 \mu \mathrm{m}$ at the entrance to $F 1$ because of the conditions at and after pass $\mathrm{P} 1$; it does not depend on what happened in the previous 15 passes.

In the first finishing stand (F1), the spreadsheet calculation suggests that the pass strain is not quite sufficient to initiate DRX, presumably because the $90^{\circ} \mathrm{C}$ temperature drop and higher strain rate make it more difficult to attain the required critical strain. However, it must be borne in mind that the calculated pass strain for $F 1$ is just less than $\varepsilon_{\mathrm{c}}$ and the redundant strain was only estimated in an approximate manner. It is quite possible therefore that DRX is actually initiated in this pass as well. At any rate, according to the spreadsheet, such softening as takes place after F1 is due to SRX. However, there is insufficient time for substantial SRX to occur, so that about half the strain is carried over to the next pass, leading to the initiation of DRX. The critical strain is also exceeded in F3, leading to MRX after that pass.

Table 1(a). Spreadsheet calculations for the $12 \mathrm{~mm}$ rod schedule, showing the grain size $0.400 \mathrm{~s}$ after the final pass.

\begin{tabular}{|c|c|c|c|c|c|c|c|c|c|c|c|c|}
\hline pass" & $\begin{array}{l}d \text { at } \\
\text { entry } \\
(\mu \mathrm{m})\end{array}$ & $\begin{array}{l}\text { temp } \\
\left({ }^{\circ} \mathrm{C}\right)\end{array}$ & $\begin{array}{c}\varepsilon \text { rate } \\
\left(s^{-1}\right)\end{array}$ & $\begin{array}{l}\text { time } \\
\text { to next } \\
\text { (s) }\end{array}$ & $\varepsilon$ & $\varepsilon_{a}$ & $\varepsilon_{\mathrm{C}}$ & $\varepsilon_{a}>\varepsilon_{c} ?$ & $\begin{array}{l}t_{0.5} \\
\text { (s) }\end{array}$ & $x$ & $\begin{array}{c}d \text { if } \\
x>0.95\end{array}$ & $\begin{array}{c}d \text { after } \\
\text { time } \\
(\mu \mathrm{m})\end{array}$ \\
\hline R 1 & 100 & 1050 & 0.90 & 15.90 & 0.45 & 0.45 & 0.23 & $Y$ & 1.163 & 1.00 & 50.1 & 50.4 \\
\hline R 2 & 50.4 & 943 & 1.48 & 13.90 & 0.51 & 0.51 & 0.30 & $Y$ & 0.492 & 1.00 & 25.7 & 26.9 \\
\hline R 3 & 26.9 & 891 & 1.65 & 9.56 & 0.63 & 0.63 & 0.32 & $Y$ & 0.297 & 1.00 & 18.5 & 20.2 \\
\hline R 4 & 20.2 & 879 & 3.25 & 5.09 & 0.69 & 0.69 & 0.35 & $Y$ & 0.154 & 1.00 & 14.7 & 17.0 \\
\hline R 5 & 17.0 & 877 & 4.08 & 3.45 & 0.51 & 0.51 & 0.34 & $Y$ & 0.104 & 1.00 & 13.8 & 16.5 \\
\hline R 6 & 16.5 & 895 & 8.77 & 2.41 & 0.71 & 0.71 & 0.36 & $Y$ & 0.068 & 1.00 & 12.9 & 16.3 \\
\hline R7 & 16.3 & 897 & 8.48 & 8.06 & 0.45 & 0.45 & 0.35 & $Y$ & 0.028 & 1.00 & 13.2 & 23.9 \\
\hline 11 & 23.9 & 992 & 23.6 & 1.23 & 0.76 & 0.76 & 0.32 & $\gamma$ & 0.047 & 1.00 & 17.7 & 21.4 \\
\hline 12 & 21.4 & 955 & 25.0 & 0.96 & 0.68 & 0.68 & 0.36 & $Y$ & 0.027 & 1.00 & 14.4 & 19.6 \\
\hline 13 & 19.6 & 971 & 40.6 & 0.74 & 0.54 & 0.54 & 0.35 & $Y$ & 0.021 & 1.00 & 14.0 & 18.6 \\
\hline 14 & 18.6 & 975 & 45.1 & 0.60 & 0.59 & 0.59 & 0.35 & $Y$ & 0.017 & 1.00 & 14.0 & 18.1 \\
\hline 15 & 18.1 & 993 & 63.7 & 0.48 & 0.49 & 0.49 & 0.34 & $Y$ & 0.015 & 1.00 & 14.2 & 17.8 \\
\hline 16 & 17.8 & 998 & 66.8 & 3.54 & 0.52 & 0.52 & 0.34 & $Y$ & 0.010 & 1.00 & 14.4 & 29.9 \\
\hline $\mathrm{P} 1$ & 29.9 & 1047 & 97.2 & 0.39 & 0.39 & 0.39 & 0.35 & $Y$ & 0.012 & 1.00 & 16.8 & 20.5 \\
\hline P 2 & 20.5 & 1037 & 83.4 & 2.28 & 0.32 & 0.32 & 0.32 & $Y$ & 0.027 & 1.00 & 16.6 & 24.8 \\
\hline F 1 & 24.8 & 947 & 250 & 0.070 & 0.56 & 0.56 & 0.57 & -- & 0.062 & 0.54 & 18.1 & 13.2 \\
\hline$F_{2}$ & 13.2 & 906 & 208 & 0.057 & 0.49 & 0.75 & 0.55 & $Y$ & 0.004 & 1.00 & & 7.1 \\
\hline F 3 & 7.1 & 929 & 422 & 0.040 & 0.60 & 0.60 & 0.46 & $Y$ & 0.004 & 1.00 & 6.5 & 6.8 \\
\hline F 4 & 6.8 & 909 & 413 & 0.400 & 0.51 & 0.51 & 0.50 & $Y$ & 0.006 & 1.00 & 5.8 & 8.3 \\
\hline
\end{tabular}

* R: Roughing, I: Intermediate, P: Prefinishing, F: Finishing 
Table 1(b). Same as above except that the grain sizes are calculated at the laying head and at the start of the austenite-to-ferrite-plus-pearlite transformation.

\begin{tabular}{|c|c|c|c|c|c|c|c|c|c|c|c|c|}
\hline pass & $\begin{array}{l}d \text { at } \\
\text { entry } \\
(\mu \mathrm{m})\end{array}$ & $\begin{array}{l}\text { temp } \\
\left({ }^{\circ} \mathrm{C}\right)\end{array}$ & $\begin{array}{c}\varepsilon \text { rate } \\
\left(s^{-1}\right)\end{array}$ & $\begin{array}{l}\text { time } \\
\text { to next } \\
\text { (s) }\end{array}$ & $\varepsilon$ & $\varepsilon_{a}$ & $\varepsilon_{\mathrm{C}}$ & $\varepsilon_{a}>\varepsilon_{c} ?$ & $\begin{array}{l}t_{0.5} \\
(s)\end{array}$ & $x$ & $\begin{array}{c}d \text { if } \\
x>0.95\end{array}$ & $\begin{array}{c}d \text { after } \\
\text { time } \\
(\mu \mathrm{m})\end{array}$ \\
\hline $\begin{array}{l}F 3 \\
F 4\end{array}$ & $\begin{array}{l}7.1 \\
6.8\end{array}$ & $\begin{array}{l}929 \\
909\end{array}$ & $\begin{array}{l}422 \\
413\end{array}$ & $\begin{array}{c}0.040 \\
3.3\end{array}$ & $\begin{array}{l}0.60 \\
0.51\end{array}$ & $\begin{array}{l}0.60 \\
0.51\end{array}$ & $\begin{array}{l}0.46 \\
0.50\end{array}$ & $\begin{array}{l}Y \\
Y\end{array}$ & $\begin{array}{l}0.004 \\
0.006\end{array}$ & $\begin{array}{l}1.00 \\
1.00\end{array}$ & $\begin{array}{l}6.5 \\
5.8\end{array}$ & $\begin{array}{c}6.8 \\
15.3\end{array}$ \\
\hline $\begin{array}{l}\text { laying } \\
\text { head }\end{array}$ & 15.3 & 850 & & 5 & & & & & & 1.00 & & \\
\hline$A_{r 3}$ & 15.5 & 800 & & & & & & & & & & \\
\hline
\end{tabular}

DRX also occurs during the final pass, followed by MRX and coarsening. About $0.015 \mathrm{~s}$ (i.e. $2.65 \times t_{0.5}$ ) after exiting this stand, the fully recrystallized grain size is calculated to be about $5.8 \mu \mathrm{m}$. Some $0.400 \mathrm{~s}$ after exiting, the grain size coarsens to about $8.3 \mu \mathrm{m}$. This prediction compares very well with Hodgson et al.'s measurement of $8 \mu \mathrm{m}$ for the surface austenite grain size about $0.4 \mathrm{~s}$ after the final pass. The latter was obtained by rapid quenching of the $12 \mathrm{~mm}$ rod in the water boxes located after the finishing block of a BHP rod mill. ${ }^{11}$

Grain coarsening continues in the time it takes for the rod to travel to the laying head, and then to begin transforming into ferrite (plus pearlite) on the forced-air cooling deck. When the exit speed of the rod is $15 \mathrm{~m} / \mathrm{s}$, and the laying head is about $49 \mathrm{~m}$ away from the final stand, about $3.3 \mathrm{~s}$ are available for grain coarsening between finish rolling and the laying head at an "average" temperature of approximately $\left(909^{\circ} \mathrm{C}+850^{\circ} \mathrm{C}\right) / 2$. Thus, the grain size at the laying head coarsens to about $15.3 \mu \mathrm{m}$ (see Table 1(b)). If the transformation starts at about $\mathrm{A}_{\mathrm{r} 3} \sim 800^{\circ} \mathrm{C}$ and the cooling rate is $10^{\circ} \mathrm{C} / \mathrm{s}$, then a further $5 \mathrm{~s}$ are available for additional grain coarsening between the laying head and the start of transformation. Thus, $d_{\nu}$ at the start of transformation is computed to be about $15.5 \mu \mathrm{m}$.

\subsection{MRX versus SRX}

The above spreadsheet results take into account the occurrence of both dynamic and metadynamic recrystallization. The combination of these two mechanisms leads to a predicted grain size $0.4 \mathrm{~s}$ after finishing $\left(d_{\gamma}=8.3 \mu \mathrm{m}\right)$, a prediction that is close to the one measured in the mill $\left(d_{\gamma}=8 \mu \mathrm{m}\right)$. As a matter of interest, it is possible to estimate the grain size that is likely to be produced if one assumes that neither DRX nor MRX can occur. An alternative spreadsheet calculation based on the SRX equations is presented in Table 2(a). It can be seen that considerable grain refinement is again predicted, but not quite to the same degree. For example, $d_{y}$ is calculated to be $11.4 \mu \mathrm{m}$ immediately after the final stand, coarsening to $14.1 \mu \mathrm{m}$ after $0.4 \mathrm{~s}$. These are substantially larger than the corresponding MRX predictions (5.8 and $8.3 \mu \mathrm{m}$, respectively). More importantly, the SRX prediction of $14.1 \mu \mathrm{m}$ is nearly twice as large as the corresponding measured grain size. This comparison therefore supports the view that DRX/MRX are indeed the dominant microstructural processes during rod rolling, ${ }^{11)}$ although more accurate relations describing the grain coarsening kinetics after both SRX and
Table 2(a). Spreadsheet calculations for the $12 \mathrm{~mm}$ rod schedule, showing the grain size $0.400 \mathrm{~s}$ after the final pass, but assuming that only SRX occurs.

\begin{tabular}{|c|c|c|c|c|c|c|c|c|c|c|}
\hline pass & $\begin{array}{l}d \text { at } \\
\text { entry } \\
(\mu \mathrm{m})\end{array}$ & $\begin{array}{l}\text { temp } \\
\left({ }^{\circ} \mathrm{C}\right)\end{array}$ & $\begin{array}{l}\varepsilon \text { rate } \\
\left(s^{-1}\right)\end{array}$ & $\begin{array}{c}\text { time } \\
\text { to next } \\
\text { (s) }\end{array}$ & $\varepsilon$ & $\varepsilon_{a}$ & $\begin{array}{l}t_{0.5} \\
\text { (s) }\end{array}$ & $x$ & $\begin{array}{c}d \text { if } \\
x>0.95\end{array}$ & $\begin{array}{c}d \text { after } \\
\text { time } \\
(\mu \mathrm{m})\end{array}$ \\
\hline R 1 & 100 & 1050 & 0.90 & 15.90 & 0.45 & 0.45 & 0.486 & 1.00 & 45.1 & 52.4 \\
\hline R 2 & 52.4 & 943 & 1.48 & 13.90 & 0.51 & 0.51 & 0.431 & 1.00 & 24.7 & 34.2 \\
\hline R 3 & 34.2 & 891 & 1.65 & 9.56 & 0.63 & 0.63 & 0.204 & 1.00 & 16.5 & 27.5 \\
\hline R 4 & 27.5 & 879 & 3.25 & 5.09 & 0.69 & 0.69 & 0.122 & 1.00 & 14.1 & 24.2 \\
\hline R 5 & 24.2 & 877 & 4.08 & 3.45 & 0.51 & 0.51 & 0.167 & 1.00 & 16.0 & 23.6 \\
\hline R 6 & 23.6 & 895 & 8.77 & 2.41 & 0.71 & 0.71 & 0.057 & 1.00 & 14.0 & 23.8 \\
\hline R 7 & 23.8 & 897 & 8.48 & 8.06 & 0.45 & 0.45 & 0.071 & 1.00 & 21.2 & 36.1 \\
\hline 11 & 36.1 & 992 & 23.6 & 1.23 & 0.76 & 0.76 & 0.026 & 1.00 & 21.4 & 31.5 \\
\hline 12 & 31.5 & 955 & 25.0 & 0.96 & 0.68 & 0.68 & 0.031 & 1.00 & 20.6 & 31.2 \\
\hline 13 & 31.2 & 971 & 40.6 & 0.74 & 0.54 & 0.54 & 0.046 & 1.00 & 24.0 & 31.1 \\
\hline 14 & 31.1 & 975 & 45.1 & 0.60 & 0.59 & 0.59 & 0.030 & 1.00 & 23.8 & 30.7 \\
\hline 15 & 30.7 & 993 & 63.7 & 0.48 & 0.49 & 0.49 & 0.039 & 1.00 & 27.0 & 31.7 \\
\hline 16 & 31.7 & 998 & 66.8 & 3.54 & 0.52 & 0.52 & 0.023 & 1.00 & 29.1 & 45.4 \\
\hline$P 1$ & 45.4 & 1047 & 97.2 & 0.39 & 0.39 & 0.39 & 0.067 & 0.98 & 40.9 & 42.5 \\
\hline $\mathrm{P} 2$ & 42.5 & 1037 & 83.4 & 2.28 & 0.32 & 0.33 & 0.210 & 1.00 & 37.0 & 39.7 \\
\hline $\mathrm{F} 1$ & 39.7 & 947 & 250 & 0.070 & 0.56 & 0.56 & 0.159 & 0.26 & 21.8 & 25.3 \\
\hline F 2 & 25.3 & 906 & 208 & 0.057 & 0.49 & 0.91 & 0.024 & 0.81 & 13.9 & 11.4 \\
\hline F 3 & 11.4 & 929 & 422 & 0.040 & 0.60 & 0.77 & 0.007 & 0.98 & 11.1 & 11.2 \\
\hline $\mathrm{F} 4$ & 11.2 & 909 & 413 & 0.400 & 0.51 & 0.52 & 0.040 & 1.00 & 11.4 & 14.1 \\
\hline
\end{tabular}

Table 2(b). Same as above except that the grain sizes are calculated at the laying head and at the start of the austenite-to-ferrite-plus-pearlite transformation.

\begin{tabular}{|c|c|c|c|c|c|c|c|c|c|c|}
\hline pass & $\begin{array}{l}d \text { at } \\
\text { entry } \\
(\mu \mathrm{m})\end{array}$ & $\begin{array}{l}\text { temp } \\
\left({ }^{\circ} \mathrm{C}\right)\end{array}$ & $\begin{array}{l}\varepsilon \text { rate } \\
\left(s^{-1}\right)\end{array}$ & $\begin{array}{l}\text { time } \\
\text { to next } \\
\text { (s) }\end{array}$ & $\varepsilon$ & $\varepsilon_{\mathbf{a}}$ & $\begin{array}{l}t_{0.5} \\
\text { (s) }\end{array}$ & $x$ & $\begin{array}{c}d \text { if } \\
x>0.95\end{array}$ & $\begin{array}{c}d \text { after } \\
\text { time } \\
(\mu \mathrm{m})\end{array}$ \\
\hline F 3 & 11.4 & 929 & 422 & 0.040 & 0.60 & 0.77 & 0.007 & 0.98 & 11.1 & 11.2 \\
\hline $\mathrm{F} 4$ & 11.2 & 909 & 413 & 3.3 & 0.51 & 0.52 & 0.040 & 1.00 & 11.4 & 23.0 \\
\hline $\begin{array}{l}\text { laying } \\
\text { head }\end{array}$ & 23.0 & 850 & & 5 & & & & 1.00 & & \\
\hline$A_{r 3}$ & 23.1 & 800 & & & & & & & & \\
\hline
\end{tabular}

MRX would clearly be useful.

The SRX spreadsheet predictions for $d_{y}$ at the laying head, and at the start of transformation, are shown in Table 2(b). These values are also substantially higher than those predicted by taking MRX into account.

\subsection{Spreadsheet for a $5.5 \mathrm{~mm}$ Rod Schedule}

The grain size evolution equations presented in Sec. 2.1 were also applied to the 25 pass schedule examined by Cetlin et al. ${ }^{17)}$ for rolling $127 \times 127 \mathrm{~mm}$ square billets down to $5.5 \mathrm{~mm}$ diameter rods. The finishing passes of this schedule involve higher strain rates and shorter interpass times than those associated with $12 \mathrm{~mm}$ product. This schedule therefore has greater potential for increased grain refinement through modifications to rod rolling practice. The pass-by-pass spreadsheet results are 
Table 3. Spreadsheet calculations for the $5.5 \mathrm{~mm}$ rod schedule described in Ref. 17), showing the grain sizes at the laying head and at the start of transformation. A cooling rate of $10^{\circ} \mathrm{C} / \mathrm{s}$ is assumed for the forced-air cooling deck.

\begin{tabular}{|c|c|c|c|c|c|c|c|c|c|c|c|c|}
\hline pass & $\begin{array}{l}d \text { at } \\
\text { entry } \\
(\mu \mathrm{m})\end{array}$ & $\begin{array}{l}\text { temp } \\
\left({ }^{\circ} \mathrm{C}\right)\end{array}$ & $\begin{array}{l}\text { E rate } \\
\left(s^{-1}\right)\end{array}$ & $\begin{array}{l}\text { time } \\
\text { to next } \\
\text { (s) }\end{array}$ & $\varepsilon$ & $\varepsilon_{a}$ & $\varepsilon_{C}$ & $\varepsilon_{a}>\varepsilon_{c} ?$ & $\begin{array}{l}t_{0.5} \\
\text { (s) }\end{array}$ & $x$ & $\begin{array}{c}d \text { if } \\
x>0.95\end{array}$ & $\begin{array}{c}\mathrm{d} \text { after } \\
\text { time } \\
(\mu \mathrm{m})\end{array}$ \\
\hline R 1 & 100 & 1050 & 0.68 & 14.5 & 0.63 & 0.63 & 0.22 & $Y$ & 1.065 & 1.00 & 53.4 & 53.8 \\
\hline R 2 & 53.8 & 980 & 0.63 & 7.6 & 0.58 & 0.58 & 0.23 & Y & 0.761 & 1.00 & 38.3 & 38.6 \\
\hline R 3 & 38.6 & 955 & 0.84 & 6.1 & 0.37 & 0.37 & 0.24 & $Y$ & 0.520 & 1.00 & 31.3 & 31.8 \\
\hline R 4 & 31.8 & 945 & 1.80 & 4.8 & 0.41 & 0.41 & 0.27 & Y & 0.268 & 1.00 & 24.9 & 26.0 \\
\hline R 5 & 26.0 & 940 & 1.57 & 3.5 & 0.54 & 0.54 & 0.25 & $Y$ & 0.361 & 1.00 & 25.0 & 25.4 \\
\hline R 6 & 25.4 & 915 & 2.40 & 2.6 & 0.53 & 0.53 & 0.30 & Y & 0.242 & 1.00 & 19.6 & 20.3 \\
\hline R 7 & 20.3 & 895 & 3.49 & 4.8 & 0.54 & 0.54 & 0.33 & Y & 0.168 & 1.00 & 15.9 & 18.0 \\
\hline 11 & 18.0 & 880 & 5.25 & 1.4 & 0.83 & 0.83 & 0.36 & $Y$ & 0.103 & 1.00 & 13.2 & 14.6 \\
\hline 12 & 14.6 & 880 & 5.08 & 1.3 & 0.60 & 0.60 & 0.34 & $Y$ & 0.106 & 1.00 & 13.3 & 14.5 \\
\hline 13 & 14.5 & 880 & 13.0 & 0.65 & 0.78 & 0.78 & 0.39 & $Y$ & 0.040 & 1.00 & 10.7 & 13.0 \\
\hline 14 & 13.0 & 900 & 9.75 & 3.0 & 0.55 & 0.55 & 0.33 & $Y$ & 0.052 & 1.00 & 13.0 & 17.8 \\
\hline$P 1$ & 17.8 & 920 & 25.5 & 0.66 & 0.65 & 0.65 & 0.39 & $Y$ & 0.025 & 1.00 & 11.7 & 15.0 \\
\hline P 2 & 15.0 & 940 & 16.7 & 0.56 & 0.43 & 0.43 & 0.32 & $Y$ & 0.037 & 1.00 & 14.5 & 17.1 \\
\hline P 3 & 17.1 & 957 & 46.2 & 0.41 & 0.75 & 0.75 & 0.37 & $Y$ & 0.017 & 1.00 & 12.6 & 15.3 \\
\hline P 4 & 15.3 & 970 & 37.1 & 3.5 & 0.53 & 0.53 & 0.33 & $Y$ & 0.023 & 1.00 & 14.2 & 23.9 \\
\hline F 1 & 23.9 & 970 & 83.7 & 0.079 & 0.58 & 0.58 & 0.43 & $Y$ & 0.010 & 1.00 & 11.8 & 12.3 \\
\hline $\mathrm{F} 2$ & 12.3 & 990 & 71.2 & 0.061 & 0.50 & 0.50 & 0.32 & $Y$ & 0.012 & 1.00 & 13.6 & 13.9 \\
\hline F 3 & 13.9 & 1005 & 121 & 0.047 & 0.55 & 0.55 & 0.34 & $Y$ & 0.008 & 1.00 & 13.0 & 13.3 \\
\hline$F 4$ & 13.3 & 1017 & 151 & 0.036 & 0.55 & 0.55 & 0.33 & $Y$ & 0.007 & 1.00 & 13.1 & 13.4 \\
\hline F 5 & 13.4 & 1026 & 314 & 0.028 & 0.63 & 0.63 & 0.36 & Y & 0.004 & 1.00 & 11.6 & 11.9 \\
\hline $\mathrm{F} 6$ & 11.9 & 1033 & 221 & 0.023 & 0.53 & 0.53 & 0.32 & $Y$ & 0.006 & 1.00 & 13.0 & 13.2 \\
\hline$F 7$ & 13.2 & 1039 & 498 & 0.018 & 0.63 & 0.63 & 0.37 & $Y$ & 0.003 & 1.00 & 11.1 & 11.3 \\
\hline F 8 & 11.3 & 1044 & 421 & 0.014 & 0.55 & 0.55 & 0.34 & $Y$ & 0.003 & 1.00 & 11.8 & 11.9 \\
\hline $\mathrm{Fg}$ & 11.9 & 1047 & 868 & 0.011 & 0.60 & 0.60 & 0.39 & $Y$ & 0.002 & 1.00 & 10.2 & 10.3 \\
\hline F10 & 10.3 & 1050 & 782 & 0.817 & 0.53 & 0.53 & 0.36 & $Y$ & 0.008 & 1.00 & 10.6 & 17.0 \\
\hline $\begin{array}{l}\text { laying } \\
\text { head }\end{array}$ & 17.0 & 900 & & 10 & & & & & & 1.00 & & \\
\hline$A_{r 3}$ & 22.8 & 800 & & & & & & & & & & \\
\hline
\end{tabular}

shown in Table 3. Note that the area strains given in Ref.17) have been multiplied by the factors described in Sec. 2.1 to take the redundant strains into account.

It is evident that all 25 pass strains are larger than the respective ones required to initiate DRX; that is to say, unlike the case of the $12 \mathrm{~mm}$ schedule, there are no sequences where the strain must be accumulated over two or more passes before DRX is initiated. It follows, of course, that the softening after every pass is by MRX. The fully recrystallized grain size after the final stand is $10.6 \mu \mathrm{m}$. At a rod exit speed of $60 \mathrm{~m} / \mathrm{s}$, and with the laying head $49 \mathrm{~m}$ away from the final stand, about $0.8 \mathrm{~s}$ are available for grain coarsening between the end of rolling and the laying head. A laying head temperature of $900^{\circ} \mathrm{C}$ and cooling rate of $10^{\circ} \mathrm{C} / \mathrm{s}$ lead to a further $10 \mathrm{~s}$ of grain coarsening, and $d_{\gamma}$ is computed to be about $22.8 \mu \mathrm{m}$ at the start of transformation.

For comparison, if only the SRX equations are used, the fully recrystallized grain size at the exit of rolling is predicted to be about $21 \mu \mathrm{m}$, and this coarsens to about $35 \mu \mathrm{m}$ at the start of transformation. This is unrealistically large, and supports the notion that MRX must be taken into account when modelling rod rolling behaviour.

\section{Modifying the $5.5 \mathrm{~mm}$ Rod Rolling Parameters to Reduce $\boldsymbol{d}_{\gamma}$}

By arranging the grain evolution equations into a computer spreadsheet, it becomes quite easy to investigate the effects of modifying rolling practice. In the sections that follow, $5.5 \mathrm{~mm}$ rod rolling simulations will be described in which modifications of the mill geometry, increases in mill speed, and reductions in rolling temperature were examined in turn. These calculations were carried out with a view to determining the minimum possible austenite grain size at the start of transformation that can be achieved by optimizing the rolling practice.

\subsection{Reducing the Time Available for $d_{\gamma}$ Coarsening}

In the computations displayed in Table 3 , the grain size immediately after the last finishing pass was about $10.6 \mu \mathrm{m}$, but this coarsened to about $22.8 \mu \mathrm{m}$ at the start of transformation. The effect of reducing the time available for coarsening was therefore investigated first.

If the laying head is moved closer to the final rolling stand-to, say, $2 \mathrm{~m}$ away-then the time interval is reduced to $0.033 \mathrm{~s}$. If the cooling rate on the forced air cooling deck is increased simultaneously to say $20^{\circ} \mathrm{C} / \mathrm{s}$, the total time to the $\mathrm{A}_{\mathrm{r} 3}$ decreases to about $5 \mathrm{~s}$. Using these new values, the austenite grain size at the start of transformation is lowered by about $10 \%$ to $d_{y}=20.4 \mu \mathrm{m}$ (see Table 4). Note, however, that virtually all of this reduction is due to the faster cooling rate after the laying head, rather than to the reduced time to reach the laying head. Thus, this approach to refining the austenite grain size is judged to be only marginally effective.

\subsection{Increasing the Strain Rate}

As indicated by Eq. (6), the MRX grain size depends on the strain rate. The calculations pertaining to a doubling of the strain rate at the final stand (to $1600 \mathrm{~s}^{-1}$ ) 
Table 4. The same conditions as for Table 3, except that the laying head is moved closer, and the cooling rate is increased to $20^{\circ} \mathrm{C} / \mathrm{s}$.

\begin{tabular}{|c|c|c|c|c|c|c|c|c|c|c|c|c|}
\hline pass & $\begin{array}{l}d \text { at } \\
\text { entry } \\
(\mu \mathrm{m})\end{array}$ & $\begin{array}{l}\text { temp } \\
\left({ }^{\circ} \mathrm{C}\right)\end{array}$ & $\begin{array}{c}\varepsilon \text { rate } \\
\left(s^{-1}\right)\end{array}$ & $\begin{array}{l}\text { time } \\
\text { to next } \\
\text { (s) }\end{array}$ & $\varepsilon$ & $\varepsilon_{a}$ & $\varepsilon_{C}$ & $\varepsilon_{\mathrm{a}}>\varepsilon_{\mathrm{c}} ?$ & $\begin{array}{l}t_{0.5} \\
(s)\end{array}$ & $x$ & $\begin{array}{c}d \text { if } \\
x>0.95\end{array}$ & $\begin{array}{c}d \text { after } \\
\text { time } \\
(\mu \mathrm{m})\end{array}$ \\
\hline$F 9$ & 11.9 & 1047 & 868 & 0.011 & 0.60 & 0.60 & 0.39 & $Y$ & 0.002 & 1.00 & 10.2 & 10.3 \\
\hline $\begin{array}{l}\text { F10 } \\
\text { laying }\end{array}$ & $\begin{array}{l}10.3 \\
10.7\end{array}$ & $\begin{array}{c}1050 \\
900\end{array}$ & 782 & $\begin{array}{c}0.033 \\
5\end{array}$ & 0.53 & 0.53 & 0.36 & $Y$ & 0.008 & $\begin{array}{l}1.00 \\
1.00\end{array}$ & 10.6 & 10.7 \\
\hline$A_{r 3}$ & 20.4 & 800 & & & & & & & & & & \\
\hline
\end{tabular}

Table 5. The same conditions as for Table 3, except that the strain rate in the last pass is doubled to $1600 \mathrm{~s}^{-1}$

\begin{tabular}{|c|c|c|c|c|c|c|c|c|c|c|c|c|}
\hline pass & $\begin{array}{l}d \text { at } \\
\text { entry } \\
(\mu: m)\end{array}$ & $\begin{array}{l}\text { temp } \\
\left({ }^{\circ} \mathrm{C}\right)\end{array}$ & $\begin{array}{l}\text { E rate } \\
\left(\mathrm{s}^{-1}\right)\end{array}$ & $\begin{array}{l}\text { time } \\
\text { to next } \\
\text { (s) }\end{array}$ & $\varepsilon$ & $\varepsilon_{a}$ & ${ }^{\varepsilon_{C}} \mathrm{C}$ & $\varepsilon_{a}>\varepsilon_{c} ?$ & $\begin{array}{l}t_{0.5} \\
(s)\end{array}$ & $x$ & $\begin{array}{c}d \text { if } \\
x>0.95\end{array}$ & $\begin{array}{c}d \text { after } \\
\text { time } \\
(\mu \mathrm{m})\end{array}$ \\
\hline$F 9$ & 11.9 & 1047 & 868 & 0.011 & 0.60 & 0.60 & 0.39 & Y & 0.002 & 1.00 & 10.2 & 10.3 \\
\hline F10 & 10.3 & 1050 & 1600 & 0.409 & 0.53 & 0.53 & 0.41 & Y & 0.004 & 1.00 & 9.0 & 13.0 \\
\hline $\begin{array}{l}\text { laying } \\
\text { head }\end{array}$ & 13.0 & 900 & & 10 & & & & & & 1.00 & & \\
\hline$A_{r 3}$ & 22.6 & 800 & & & & & & & & & & \\
\hline
\end{tabular}

Table 6. Spreadsheet calculations for the $5.5 \mathrm{~mm}$ rod schedule, where the temperatures at all the passes have been lowered by $60^{\circ} \mathrm{C}$. (Only the finishing passes are shown here.)

\begin{tabular}{|c|c|c|c|c|c|c|c|c|c|c|c|c|}
\hline pass & $\begin{array}{l}d \text { at } \\
\text { entry } \\
(\mu \mathrm{m})\end{array}$ & $\begin{array}{l}\text { temp } \\
\left({ }^{\circ} \mathrm{C}\right)\end{array}$ & $\begin{array}{c}\text { \& rate } \\
\left(\mathrm{s}^{-1}\right)\end{array}$ & $\begin{array}{l}\text { time } \\
\text { to next } \\
\text { (s) }\end{array}$ & $\varepsilon$ & $\varepsilon_{a}$ & $\varepsilon_{\mathrm{C}}$ & $\varepsilon_{\mathrm{a}} \varepsilon_{\mathrm{C}} ?$ & $\begin{array}{l}t_{0.5} \\
\text { (s) }\end{array}$ & $x$ & $\begin{array}{c}d \text { if } \\
x>0.95\end{array}$ & $\begin{array}{c}d \text { after } \\
\text { time } \\
(\mu \mathrm{m})\end{array}$ \\
\hline F 1 & 20.9 & 910 & 83.7 & 0.079 & 0.58 & 0.58 & 0.53 & $Y$ & 0.009 & 1.00 & 8.4 & 8.8 \\
\hline F 2 & 8.8 & 930 & 71.2 & 0.061 & 0.50 & 0.50 & 0.36 & $Y$ & 0.012 & 1.00 & 9.8 & 10.0 \\
\hline F 3 & 10.0 & 945 & 121 & 0.047 & 0.55 & 0.55 & 0.39 & $Y$ & 0.008 & 1.00 & 9.5 & 9.7 \\
\hline $\mathrm{F} 4$ & 9.7 & 957 & 151 & 0.036 & 0.55 & 0.55 & 0.38 & $Y$ & 0.007 & 1.00 & 9.6 & 9.8 \\
\hline F 5 & 9.8 & 966 & 314 & 0.028 & 0.63 & 0.63 & 0.42 & $Y$ & 0.004 & 1.00 & 8.5 & 8.7 \\
\hline F 6 & 8.7 & 973 & 221 & 0.023 & 0.53 & 0.53 & 0.37 & $Y$ & 0.005 & 1.00 & 9.6 & 9.7 \\
\hline F 7 & 9.7 & 979 & 498 & 0.018 & 0.63 & 0.63 & 0.43 & $Y$ & 0.003 & 1.00 & 8.2 & 8.4 \\
\hline$F 8$ & 8.4 & 984 & 421 & 0.014 & 0.55 & 0.55 & 0.39 & $Y$ & 0.003 & 1.00 & 8.7 & 8.8 \\
\hline$F \theta$ & 8.8 & 987 & 868 & 0.011 & 0.60 & 0.60 & 0.44 & $Y$ & 0.002 & 1.00 & 7.5 & 7.6 \\
\hline $\mathrm{F} 10$ & 7.6 & 990 & 782 & 0.817 & 0.53 & 0.53 & 0.41 & $Y$ & 0.005 & 1.00 & 7.8 & 14.1 \\
\hline $\begin{array}{l}\text { laying } \\
\text { head }\end{array}$ & 14.1 & 900 & & 10 & & & & & & 1.00 & & \\
\hline$A_{r 3}$ & 19.6 & 800 & & & & & & & & & & \\
\hline
\end{tabular}

are illustrated in Table 5. Here, all the other parameters have been held constant, except the time to the laying head, which is halved. It can be seen that $d_{\gamma}$ at the start of transformation remains close to $23 \mu \mathrm{m}$. The reason is that, although increasing the strain rate reduces $d_{\gamma}$ somewhat at the exit of the final stand, the time to transformation remains virtually the same, and the coarsened grain size at the end of that time is not very sensitive to the initial grain size (Eq. (8)).

\subsection{Reducing the Temperatures of All the Passes}

Equation (6) also indicates that the MRX grain size decreases as the temperature is decreased, although there is a limit to how much the temperatures can be lowered throughout the mill and still have rolling take place in the austenite-only regime. The lower rolling temperatures could be achieved, for example, by lowering the reheat furnace drop-out temperature. Inspection of Table 3 shows that the temperature decreases through the initial stands of rod rolling, but then increases through the pre-finishing and finishing stands. The minimum is reached during intermediate rolling, and is about $880^{\circ} \mathrm{C}$ for the present schedule. For plain $\mathrm{C}$ grades containing around 0.06 to $0.10 \% \mathrm{C}$, the equilibrium austenite-to(ferrite + pearlite) transformation start temperature $A_{r 3}$ is about $850^{\circ} \mathrm{C}$. A spreadsheet is shown in Table 6 where the temperatures at all the passes have been reduced by $60^{\circ} \mathrm{C}$. This is probably the maximum reduction compatible with rolling still taking place in the austeniteonly regime. (In fact, lowering the reheat temperature by $60^{\circ} \mathrm{C}$ is unlikely to reduce the temperature in all passes by that amount. This is because the increased strength at lower temperatures leads to more deformation heating. However, for the purposes of the present analysis, this subtlety is ignored.)

Even though the critical strains for DRX have increased somewhat because of the lowered temperatures, MRX still occurs through the finishing block, leading to a recrystallized grain size of $7.8 \mu \mathrm{m}$ immediately after the final stand. Assuming that the laying head temperature is lowered to $850^{\circ} \mathrm{C}$, but the cooling rate and transformation start temperature retain their previous values (cooling rate $=10^{\circ} \mathrm{C} / \mathrm{s}, \mathrm{A}_{\mathrm{r} 3} \sim 800^{\circ} \mathrm{C}$ ), the austenite grain size at the start of transformation is computed to 
Table 7. Spreadsheet calculation for the $5.5 \mathrm{~mm}$ rod schedule, where only the finishing pass temperatures have been lowered by $150^{\circ} \mathrm{C}$.

\begin{tabular}{|c|c|c|c|c|c|c|c|c|c|c|c|c|}
\hline pass & $\begin{array}{l}d \text { at } \\
\text { entry } \\
(\mu \mathrm{m})\end{array}$ & $\begin{array}{l}\text { temp } \\
\left({ }^{\circ} \mathrm{C}\right)\end{array}$ & $\begin{array}{l}\text { \& rate } \\
\left(\mathrm{s}^{-1}\right)\end{array}$ & $\begin{array}{l}\text { time } \\
\text { to next } \\
\text { (s) }\end{array}$ & $\varepsilon$ & $\varepsilon_{a}$ & $\varepsilon_{C}$ & $\varepsilon_{a} \cdot \varepsilon_{c} ?$ & $\begin{array}{l}t_{0.5} \\
\text { (s) }\end{array}$ & $x$ & $\begin{array}{c}d \text { if } \\
x>0.95\end{array}$ & $\begin{array}{c}d \text { after } \\
\text { time } \\
(\mu \mathrm{m})\end{array}$ \\
\hline F 1 & 17.2 & 820 & 83.7 & 0.079 & 0.58 & 0.58 & 0.76 & -- & 0.216 & 0.22 & 10.4 & 11.8 \\
\hline F 2 & 11.8 & 840 & 71,2 & 0.061 & 0.50 & 0.95 & 0.60 & $\gamma$ & 0.010 & 1.00 & 5.6 & 5.8 \\
\hline F 3 & 5.8 & 855 & 121 & 0.047 & 0.55 & 0.55 & 0.49 & $Y$ & 0.007 & 1.00 & 5.5 & 5.7 \\
\hline F 4 & 5.7 & 867 & 151 & 0.036 & 0.55 & 0.55 & 0.48 & $Y$ & 0.006 & 1.00 & 5.6 & 5.8 \\
\hline F 5 & 5.8 & 876 & 314 & 0.028 & 0.63 & 0.63 & 0.52 & $\gamma$ & 0.004 & 1.00 & 5.0 & 5.2 \\
\hline F 6 & 5.2 & 883 & 221 & 0.023 & 0.53 & 0.53 & 0.46 & $Y$ & 0.005 & 1.00 & 5.7 & 5.8 \\
\hline$F 7$ & 5.8 & 889 & 498 & 0.018 & 0.63 & 0.63 & 0.53 & $Y$ & 0.003 & 1.00 & 4.9 & 5.0 \\
\hline F 8 & 5.0 & 894 & 421 & 0.014 & 0.55 & 0.55 & 0.49 & $Y$ & 0.003 & 1.00 & 5.3 & 5.3 \\
\hline F 9 & 5.3 & 897 & 868 & 0.011 & 0.60 & 0.60 & 0.55 & $Y$ & 0.002 & 1.00 & 4.5 & 4.6 \\
\hline F10 & 4.6 & 900 & 782 & 0.817 & 0.53 & 0.53 & 0.51 & $Y$ & 0.003 & 1.00 & 4.7 & 9.6 \\
\hline $\begin{array}{l}\text { laying } \\
\text { head }\end{array}$ & 9.6 & 850 & & 5 & & & & & & 1.00 & & \\
\hline$A_{r 3}$ & 14.2 & 800 & & & & & & & & & & \\
\hline
\end{tabular}

be $18.0 \mu \mathrm{m}$. That is, lowering the rolling temperature by $60^{\circ} \mathrm{C}$ leads to about $20 \%$ reduction in $d_{\gamma}$.

\subsection{Reducing the Temperatures of the Finishing Passes}

An alternative to lowering the temperature throughout rolling, is only to lower it prior to entering the finishing block. This can be done by introducing a water box immediately after the pre-finishing stands (as for the $12 \mathrm{~mm}$ schedule discussed in Sec. 2.3). If the temperatures throughout finishing are lowered by $150^{\circ} \mathrm{C}$, so that $\mathrm{F} 1 \sim 820^{\circ} \mathrm{C}$ and $\mathrm{F} 10 \sim 900^{\circ} \mathrm{C}$, this leads to $d_{\gamma}$ at transformation of $14.2 \mu \mathrm{m}$ (Table 7). This can be further reduced to about $13 \mu \mathrm{m}$ by simultaneously increasing the forced-air cooling rate to $20^{\circ} \mathrm{C} / \mathrm{s}$.

Recalling Eq. (6), if the softening throughout is by MRX, the grain size after the final stand is determined only by the conditions at that stand. This suggests another possible modification to the mill layout: water cooling applied immediately after stand F10 to lower the temperature to around $850^{\circ} \mathrm{C}$ (i.e. as low as possible in the austenite-only regime), followed by a single additional pass*. The strain at this pass, however, would have to be quite large in order to exceed the critical strain for DRX at this low temperature (from Eq. (1), $\varepsilon_{\mathrm{c}} \sim 0.65$ at $T=850^{\circ} \mathrm{C}$ and $\dot{\varepsilon}=800 \mathrm{~s}^{-1}$ ). For an additional pass of $\varepsilon=0.70$ at $T=850^{\circ} \mathrm{C}$ and $\dot{\varepsilon}=800 \mathrm{~s}^{-1}$, followed $0.5 \mathrm{~s}$ later by the laying head at $820^{\circ} \mathrm{C}$ and forced air cooling at $20^{\circ} \mathrm{C} / \mathrm{s}$, the austenite grain size at the start of transformation would be lowered to about $10.2 \mu \mathrm{m}$.

This is probably the limit achievable by adjustments to the austenite rolling practice. Depending on the cooling rates through the transformation, this should lead to ferrite grain sizes in the 5 to $7 \mu \mathrm{m}$ range.

\subsection{Comments on Grain Refinement by MRX}

The present analysis indicates that MRX is the recrystallization process responsible for grain size evolution during the rod rolling of plain low $\mathrm{C}$ grades. Because of this, the grain size at the end of rolling depends only on the conditions of the final pass, followed by the grain coarsening behaviour up to the beginning of transformation. This contrasts with rolling processes in which conventional SRX is dominant; here, the final grain size depends a great deal upon conditions in the previous passes. In a sense, "MRX controlled rolling" essentially consists of lowering the temperature (but remaining in the austenite-only regime), so that the recrystallized grain size is as fine as possible, and so that the time and temperature for coarsening are minimized. As such, the design of rolling schedules that lead to maximum grain refinement by MRX requires that accurate equations be developed for describing the transition from SRX to MRX, as well as for characterizing the grain coarsening behaviour.

Not considered in this study were the effects of microalloying additions, such as $\mathrm{Nb}$ and $\mathrm{Ti}$, on the production of fine austenite grain sizes. The presence of finely divided TiN particles can reduce the extent of grain coarsening after MRX. Similarly, the solute drag attributable to $\mathrm{Nb}$ in solution can also act to reduce the recrystallized grain size. The equations used above are not applicable to such grades. Therefore, if further lower limits to $d_{\gamma}$ are to be estimated using spreadsheet simulations of the present type, equivalent relations would have to be determined for the microalloyed grades.

\section{Conclusions}

(1) By incorporating the evolution equations for austenite grain size into commonly-used spreadsheet software, the pass-by-pass evolution of austenite grain size can be studied. The present analysis indicates that MRX is the recrystallization process responsible for grain size evolution during the rod rolling of plain low $\mathrm{C}$ grades, and this is confirmed by mill grain size measurements made previously.

(2) The spreadsheet can be employed to examine the effects of modifications to rod rolling practice. In terms of austenite grain refinement during a $5.5 \mathrm{~mm}$ rod rolling schedule, little benefit is obtained by increasing the strain rate, or by reducing the distance from the final rolling pass to the laying head. By contrast, increasing the

* An additional pass is suggested here because of the requirement to cool between the last and next-to-last stands. This would not be possible between stands F9 and F10 of the above mill because all the finishing stands are contained within an enclosed "block" and are separated by only $0.6 \mathrm{~m}$. 
cooling rate on the forced-air cooling deck should lead to measurable austenite grain refinement.

(3) Lowering the temperatures during rolling also leads to grain refinement. In the $5.5 \mathrm{~mm}$ rod schedule studied, if the temperatures at all stands are lowered by $60^{\circ} \mathrm{C}$-for example, by lowering the furnace drop-out temperature - the grain size is reduced by approximately $10 \%$. If only the temperatures in the finishing stands are lowered-say, by water cooling by $150^{\circ} \mathrm{C}$ just before finishing - additional grain refinement of more than $35 \%$ can be achieved. If water cooling is applied after the finishing block, together with a single additional deformation applied just above the transformation temperature, the grain refinement with respect to conventional practice can amount to $50 \%$ or more.

(4) Combining the water cooling +additional deformation approach with a higher forced-air cooling rate can lead to an austenite grain size at the beginning of transformation of about $10 \mu \mathrm{m}$ in plain $\mathrm{C}$ grades. This is probably the limit that can be achieved by fine-tuning a typical rod finishing schedule. Further reductions appear to be possible by switching to microalloyed grades.

\section{Acknowledgments}

The authors gratefully acknowledge the financial support of the Canadian Steel Industry Research Association (CSIRA) and the Natural Sciences and Engineering Research Council of Canada (NSERC). Thanks are also due to Mr. M. Pham of Unimétal Recherche, Amneville, France for financial support and many useful discussions during the early part of this work, and to Mr. R. Gloss of BHP Research for his comments. One of the authors (PDH) also wishes to acknowledge the ongoing support of the Rod and Bar Products Division of BHP Steel.

\section{REFERENCES}

1) P. D. Hodgson, R. E. Gloss and G. L. Dunlop: 32nd Annual Mechanical Working and Steel Processing Conf., Iron and Steel Soc. of AIME, Warrendale, USA, (1991), 527.

2) J. J. Jonas: Mater. Sci. Eng., A184 (1994), 155.

3) R. A. Petkovic, M. J. Luton and J. J. Jonas: Can. Metall. Q., 14 (1975), 137.

4) R. A. Petkovic, M. J. Luton and J. J. Jonas: Acta Metall., 27 (1979), 1633.

5) J. J. Jonas: Int. Conf. Recrystallization in Metallic Materials-. Recrystallization ' 90 , ed. by T. Chandra, Metallurgical Soc. of AIME, Warrendale, USA, (1990), 27.

6) C. Roucoules, P. D. Hodgson, S. Yue and J. J. Jonas: Metall. Trans. A, 25A (1994), 389.

7) P. Choquet, A. LeBon and C. Perdrix: Proc. 7th Int. Conf. Strength of Metals and Alloys (ICSMA 7), ed. by H. J. McQueen et al., Pergamon Press, New York, (1985), 1025.

8) F. Boratto, S. Yue, J. J. Jonas and T. H. Lawrence: Proc. Int. Conf. on Physical Metallurgy of Thermomechanical Processing of Steels and other Metals (THERMEC '88), ed. by I. Tamura, Iron and Steel Inst. Japan, Tokyo, (1988), 519.

9) P. D. Hodgson and R. K. Gibbs: ISIJ Int., 32 (1992), 1329.

10) C. M. Sellars: Mater. Sci. Technol, 6 (1990), 1072.

11) P. D. Hodgson, L. O. Hazeldon, D. L. Matthews and R. E. Gloss: Proc. Int. Conf. Microalloying '95, ed. by M. Korchynsky et al., Iron and Steel Soc. of AIME, Warrendale, USA, (1995), 341.

12) J. H. Beynon and C. M. Sellars: ISIJ Int., 32 (1992), 359.

13) E. Scheil: Arch. Eisenhüttenwes., 12 (1935), 565.

14) P. D. Hodgson, J. J. Jonas and S. Yue: Mater. Sci. Forum, 94-96 (1992), 715.

15) W. F. Hosford and R. M. Caddell: Metal Forming: Mechanics and Metallurgy, 2nd Ed., PTR Prentice Hall, Englewood Cliffs, USA, (1993), 226.

16) I. P. Kemp: Ironmaking Steelmaking, 17 (1990), 139.

17) P. R. Cetlin, S. Yue, J. J. Jonas and T. M. Maccagno: Metall. Trans. A, 24A (1993), 1543. 